\title{
THE ROLE OF COMMUNITY WELFARE CENTERS TO ENHANCE COMMUNITY DISASTER RESILIENCE
}

\author{
JUHEE KIM, SOJEONG LEE, HYEMIN KWON \& DAMI KIM \\ Pusan National University, South Korea
}

\begin{abstract}
For effective disaster management, contemporary society requests a pursuit of a new approach which is related to the concept of CDR (Community Disaster Resilience), focusing more on the adaptation to and ability to deal with unpredictable disaster risks. This study notes community welfare centers play an intermediary role to include the community as a part of the disaster management system. Community welfare centers, which carry out the various roles based on the regional features, could be an essential part of building the effective disaster management system through enhancement of CDR. Nevertheless, nowadays when a disaster occurs, community welfare centers are performing the minimal functions due to the ambiguity in the roles of the community welfare centers. For this reason, it is required that we find out the role of community welfare centers in terms of improving CDR. The point of this study is to define the concept of resilience and to find the roles of community welfare centers through literature reviews. The survey questions were about the level of performance of their traditional CDR related services derived from basic elements of CDR. Also, the importance of both services is measured by the social workers in community welfare centers in Busan, South Korea. The collected data was analyzed. The result is meaningful to find the role community welfare centers to improve CDR and its implication to social welfare practice is to be presented.

Keywords: community disaster resilience, community welfare center, social welfare practice, disaster.
\end{abstract}

\section{INTRODUCTION}

One of promising strategies of disaster management is the CDR (Community Disaster Resilience) based method. CDR can be understood as a concept that emphasizes the ability of community coping with disasters, admitting limitations of traditional disaster management: the government-oriented method, as the impact of disasters is critical to the community.

The main strategies of a CDR based disaster management system contain improving disaster coping skills of the community through making stronger social structural, cultural, and political foundation as well as developing the physical environment to utilize the various resources in society. Therefore, the role of active community members' participation is truly important since CDR based system pays attention to community-level actions. However, some researchers consider CDR as an administrative or technical relevant issue. For this reason, the practical way of dealing with the concept of CDR should be discussed.

It is required to determine who should take the responsibility of making a safe society from the constant danger of disaster while CDR based disaster management is unfamiliar in Korea. This study suggests community welfare centers can be one participant to perform CDR. In the traditional way of disaster management system, the role of community welfare centers is limited. However, they are expected to perform the key role when it comes to CDR since community welfare centers have offered various types of social services that help people improve their quality of life based on the specialty of each community. This links to the essence of improving CDR. Including community welfare centers in disaster management system will bring positive effects since the goal of them is to make the community a better place by taking care of their people. In this regard, the purpose of this study is to explore 
what is the role of community welfare centers concerning improvement of CDR based on their traditional functioning.

\section{LITERATURE REVIEWS}

\subsection{Why CDR is important: the definition of CDR}

The concept called resilience has covered in various academic fields. Ecologists introduced it for the first time. Holling [1] defined resilience as environmental capability to maintain the identical relationships between populations or state variable absorbing change and disturbance. In the field of psychology and social work, resilience refers to the personal ability that experiences growth after dealing with difficulties and stress in one's life [2]-[5]. Even though the concept might be interpreted in different levels depending on the person or academic field, the common notion of resilience means to power to go back to normal circumstance or even make improve in the end when facing negative experiences.

Timmerman [6] was the first who tried to apply resilience to disaster management. He called resilience the ability to recover and absorb the occurrence of disasters. Recently, the more serious and complex disaster will occur because of the changing society. For this reason, the shift in paradigm from government-based to community-based disaster management system is requested as a result of recognizing the importance of the community's role. In this way, the concept of CDR is noticeable when regarding the ability of community to deal with difficulties caused by disasters and overcome the situation. Specifically, even though occurrence of natural disaster cannot prevent perfectly, it is possible to reduce its impact by enhancing CDR [7]. Mayunga [8] mentioned that understanding of CDR is more important than just focusing on vulnerability to hazard in recent days [9]. Australia and England already have focused on CDR, which includes not only the recovery ability but also assessment of vulnerability in the community [7]. Furthermore, a number of nations in Southeast Asia have implemented CBDRM (Community Based Disaster Risk Management). The community itself is the main performer of CBDRM to empower its members' ability to respond and prevent vulnerability from negative impact of disasters [10], [11]. The community voluntarily takes part in the whole disaster management process. During the process, many participants including residents try to do a bottom-up approach cooperating with governmental institutions as well as sharing their experience and distinctive methods of disaster management [10]. In this way, CDR based disaster management is considered as a useful way of disaster management.

\subsection{Community welfare centers: the performers of enhancing CDR}

It is required to determine who would perform the activities using CDR based approach. Many scholars have claimed that the role of community is essential since volunteer groups and other community based organizations have conducted a key role during the entire disaster management stages despite the central governmental support [12]. In other words, participation of community based organizations is critical to quick response when disasters virtually occur. In addition, the democratic way of decision-making process based on the active participation of relevant agents and credibility to government institutions during the chaotic situation [13].

This study notes the possibility that the community welfare centers can take an important role for improving CDR based on the literature reviews mentioned above. A number of research results and experiences should be accumulated to make a disaster-resistant 
community. Social, cultural, geographical, demographical, or any other factors related to the community also need to be concerned [14]. Community welfare centers in Korea is the place equipped with specialized professionals and infrastructure where people can receive comprehensive social services and cooperate with other participants including community members to solve their own problems in the community [15]. Therefore, the goal of community welfare centers has to do with enhancement of CDR in terms of dealing with needs and problems and encouraging people to be involved in the process. The specific services that community welfare centers offer are shown in Table 1.

It is hardly shown in the previous research that the services provided by community welfare centers are related to improve CDR. However, a few research results imply that the community welfare centers can offer services to improve CDR. They support to solve problems and integrate the whole society [16]. Furthermore, community welfare centers

Table 1: Services of community welfare centers.

\begin{tabular}{|c|c|c|}
\hline Function & Section & Service \\
\hline \multirow{3}{*}{$\begin{array}{l}\text { Case } \\
\text { Management }\end{array}$} & Exploring Cases & Case development \\
\hline & Casework & Casework \\
\hline & Networking Services & Linking services \\
\hline \multirow{4}{*}{$\begin{array}{l}\text { Providing } \\
\text { Services }\end{array}$} & Family empowerment & $\begin{array}{l}\text { 1.Family relations program } \\
\text { 2.Family support program } \\
\text { 3.Family therapy program } \\
\text { 4.Family caregivers support } \\
\text { 5.Specialty based program }\end{array}$ \\
\hline & Protecting community & $\begin{array}{l}\text { 1.Meal support program } \\
\text { 2.Healthcare services } \\
\text { 3.Financial support } \\
\text { 4.Daily Life support } \\
\text { 5.Mental care } \\
\text { 6.Temporary support } \\
\text { 7.In-home care }\end{array}$ \\
\hline & Education/culture & $\begin{array}{l}\text { 1.Child education } \\
\text { 2.Adult education } \\
\text { 3.Elderly leisure/culture } \\
\text { 4.Culture welfare }\end{array}$ \\
\hline & Self-reliance program & $\begin{array}{l}\text { 1.Job training } \\
\text { 2.Employment services } \\
\text { 3.Job ability education } \\
\text { 4.Others }\end{array}$ \\
\hline \multirow{3}{*}{$\begin{array}{l}\text { Organizing } \\
\text { Community }\end{array}$} & Building networks & $\begin{array}{l}\text { 1.Community network services } \\
\text { 2.Community need assessment } \\
\text { 3.Supervision }\end{array}$ \\
\hline & $\begin{array}{l}\text { Community } \\
\text { organization }\end{array}$ & $\begin{array}{l}\text { 1.Community services } \\
\text { 2.Community organization } \\
\text { 3.Community education }\end{array}$ \\
\hline & $\begin{array}{l}\text { Developing/managing } \\
\text { resources }\end{array}$ & $\begin{array}{l}\text { 1.Volunteer management } \\
\text { 2.Sponsor management }\end{array}$ \\
\hline
\end{tabular}


focuses on the viewpoint of empower the community's capacity that allows people to adapt and overcome the difficult situation during the overall disaster management stages. These can support the reason why community welfare centers participate in disaster management process for the community. However, the role of community welfare centers has been limited so far. For example, they only have done disaster relief activities in disaster affected regions without professional background. For now, it is important to establish the role of social welfare practice in the disaster management area regarding enhancement of CDR.

\subsection{The elements of CDR}

In reality, it is hard to understand the practical aspect of CDR without knowing the basic elements of CDR and how to measure it. The assessment of CDR is useful to set a priority when disaster related policies are developed [12]. A variety of elements should be considered

Table 2: Elements of CDR (proposed).

\begin{tabular}{|c|c|c|}
\hline Dimension & Element & Indicator \\
\hline \multirow{6}{*}{$\begin{array}{l}\text { Social } \\
\text { Dimension }\end{array}$} & $\begin{array}{l}\text { 1.Disaster } \\
\text { vulnerability }\end{array}$ & $\begin{array}{l}\text { Percent of the population over } 65, \\
\text { Percent of population under } 4, \\
\text { Percent of the disabled, } \\
\text { Percent of registered foreigners, } \\
\text { Percent of Recipients of the National Basic } \\
\text { Livelihood Security Program }\end{array}$ \\
\hline & $\begin{array}{l}\text { 2.Accessibility } \\
\text { to information }\end{array}$ & $\begin{array}{l}\text { Percent of mobile phone user, } \\
\text { Percent of the Internet user }\end{array}$ \\
\hline & $\begin{array}{l}\text { 3.Health/welfare } \\
\text { facilities }\end{array}$ & $\begin{array}{l}\text { Number of health/social welfare related } \\
\text { professional per } 1000 \text { population, } \\
\text { Number of medical clinics, } \\
\text { social welfare facilities }\end{array}$ \\
\hline & $\begin{array}{l}\text { 4.Facilities } \\
\text { for disaster victims }\end{array}$ & $\begin{array}{l}\text { The number of temporary shelters for } \\
\text { disaster victims }\end{array}$ \\
\hline & $\begin{array}{l}\text { 5.Disaster } \\
\text { mitigation }\end{array}$ & $\begin{array}{l}\text { Percent of population perceiving the society } \\
\text { as a safe place, } \\
\text { Number of fire stations/officers }\end{array}$ \\
\hline & $\begin{array}{l}\text { 6.Social } \\
\text { participation } \\
\text { /integration }\end{array}$ & $\begin{array}{l}\text { Percent of population participating civic } \\
\text { organizations, } \\
\text { Number of volunteering groups, } \\
\text { Percent of population who trusts public } \\
\text { institutions }\end{array}$ \\
\hline \multirow{2}{*}{$\begin{array}{l}\text { Economic } \\
\text { Dimension }\end{array}$} & 1.Finance & $\begin{array}{l}\text { Self-reliance ratio of local finance, GRDP, } \\
\text { safety budget, percent of employment }\end{array}$ \\
\hline & $\begin{array}{l}\text { 2.Population with } \\
\text { health insurance }\end{array}$ & Population with health insurance \\
\hline \multirow{3}{*}{$\begin{array}{l}\text { Physical/ } \\
\text { Environmental } \\
\text { Dimension }\end{array}$} & 1.Housing & Percent of Deteriorated/vulnerable buildings \\
\hline & 2.Transportation & Number of registered automobile \\
\hline & 3.Hazard occurrence & Frequency of natural disaster, property loss \\
\hline
\end{tabular}


when measuring CDR as it is a multi-dimensional level concept including both the community's capacity and vulnerability [17]. Many researchers have tried to design the index to measure the level of CDR. Mayunga [8] composed CDRF (Community Disaster Resilience Framework) using four types of capital (social capital, financial capital, physical capital, human capital). Cutter et al. [19] and Burton [20] introduced variables categorized as social resilience, economic resilience, institutional resilience, infrastructure resilience, environmental systems resilience, and community capital. Kim et al. [7] suggested two types of variables, social dimension and physical dimension. Kim et al. [21] suggest CDRF derived inductively from case study, Kang et al. [22] tried to measure CDR through quantitative variables such as recovery costs and property damages. Yoon et al. [17] used twenty-four indicators that are suitable for Korea divided into human aspect, social aspect, economic aspect, physical aspect, and environmental aspect. This study suggests three aspects of CDR based on Yoon et al.'s study result and eleven elements included each aspect.

\section{METHOD}

\subsection{Subjects and data collection}

In this study, 92 questionnaires were distributed to 46 community welfare centers among total 53 community welfare centers in Busan, except the seven community welfare centers where they did not respond. More than two social workers including at least one middle manager and one general worker were required to complete a questionnaire in each community welfare center. The data were collected by facing, mailings, and through a fax during Jan. $9^{\text {th }}$ to $31^{\text {st }} 2017$. A total of 70 collected data from 34 community welfare centers were analyzed.

\subsection{Study design and analysis method}

This study conducted research survey asking the level of performance of services that the Ministry of Health and Welfare [15] encourage the community welfare centers to follow and how much the services are related to enhancement of CDR. Therefore, IPA (Importance Performance Analysis) was applied to compare and analyze the relative importanceperformance simultaneously, in regard to each task. It draws priorities of numerous tasks and figures out mean value of each variable presented on the matrix.

This study composed questionnaires regarding: 1) performance of the community welfare centers' traditional services and its importance to improve CDR, and 2) the importance and performance of services related to CDR improvement. As for the CDR-IPA questions, the specific roles of community welfare centers during disasters have not been suggested. Thus, the CDR IPA questions were referred to precedent research and composed the questions by considering both official guideline for community welfare centers' services (guided by the

Table 3: IPA matrix [23].

\begin{tabular}{|c|c|c|c|}
\hline high & \multicolumn{2}{|c|}{ Concentrate here } & \multicolumn{2}{c|}{ Keep up the good work } \\
\hline importance(I) & \multicolumn{2}{|c|}{ Low priority } & \multicolumn{2}{c|}{ Possible overkill } \\
\hline low & low & \multicolumn{2}{|c|}{ performance(P) } \\
\hline
\end{tabular}


Ministry of Health and Welfare) and the elements of CDR. The questionnaire was reviewed by experts, a disaster welfare specialist and a community welfare specialist gave consultant to improve the validity. The Likert scale was used for the survey. In regard to performance, the choices range from "Never (1)" to "Very often (5)". As to the importance of CDR, it was measured in the scale of "Not important at all (1)" to "Very important (5)". Data were analyzed with frequency analysis, pared t-test and mean analysis through the IPA matrix using SPSS WIN 22.2 program.

\section{FINDINGS}

\subsection{The common properties of the surveyed institutions}

As to the surveyed community welfare centers, $61.4 \%$ were categorized as "Ga-type", $35.7 \%$ as "Na-type", and 2\% as "Da-type". As to their locales, $31.4 \%$ were located in mixed lower/middle class areas, $30 \%$ in permanent rental apartments, $25.7 \%$ in lower-class concentrated areas, and $12.9 \%$ in other areas. As to their establishment type, governmental funded was most common at $47 \%$. As to the operator, social welfare foundations were the most common at 55\%. Among the respondents from the institutions, "Higher than middle manager" turned out at $57.1 \%$ with 40 people, and social workers at $42.9 \%$ with 30 people.

\subsection{Technical statistics analysis of importance-performance}

4.2.1 The importance in CDR and the performance of community welfare service.

According to the reliability analysis of all responses, the Cronbach $\alpha$ value was 0.948 , indicating a high response reliability. As to the importance-performance analysis of all responses, the importance of CDR improvement appeared to be more significant than the community welfare centers' performance. The difference was statistically significant $(\mathrm{P}<.001)$. According to the analysis of all 3 roles of community welfare centers, importance appeared more significant than performance, and the difference was statistically significant $(\mathrm{P}<.05, \mathrm{P}<.001)$ in case management and providing services.

As to the analysis of the 10 sections of community welfare centers, in 7 sections excluding "Education/culture", "Building network", and "Developing/managing resources", the importance in CDR improvement appeared to be more significant than performance. Among these, the difference was statistically significant $(\mathrm{P}<.05)$ in 6 sections excluding "Case work". As to "Education/culture" and "Developing/managing resources", the importance in CDR improvement appeared less significant than performance. Only the difference in "Education/culture" was statistically significant $(\mathrm{P}<.001)$. As for "Building network", the mean value of importance and performance were on a par with each other.

The analysis of the centers' services also showed that importance was generally more significant than performance. However, the entire services in "education/ culture" and "Developing/managing resources" as well as "Mental care" and "Supervision" showed the opposite. "Case development" and "Linking services" in the case management section, "Family relations program", "Family therapy program" and "Family caregivers support" in the section of "Family empowerment" showed the significant statistical difference $(\mathrm{P}<.05)$. In the "Protecting community" section, only the "Healthcare services" and "Temporary support" showed a significant difference $(\mathrm{P}<.05)$. As to "Education/culture" and "Selfreliance program" sections, all services showed significant statistical differences in importance-performance $(\mathrm{P}<.05)$. In the community organization section, only "Supervision" and "Community education" showed a significant difference $(\mathrm{P}<.05)$. 
4.2.2 Importance and performance in services related to CDR improvement

According to the reliability analysis of all responses, the Cronbach $\alpha$ value was 0.956 , indicating the high response reliability. As to the importance-performance analysis of all responses, the importance appeared more significant than performance on average, indicating a statistically significant difference $(\mathrm{P}<.001)$. According to the analysis of the average of CDR's three dimensions, in all three (social, economic, physical-environmental) aspects, importance appeared more significant than performance. The differences were all statistically significant $(\mathrm{P}<0.001)$. According to the analysis of the 11 components of $\mathrm{CDR}$, the importance appeared more significant than performance in 10 components excluding "Housing". All the differences in values were statistically significant $(\mathrm{P}<0.001)$. Likewise, according to the analysis of CDR-related services, all 25 parts indicated that importance is more significant than performance. All the differences in values were significant $(\mathrm{P}<0.05)$ except for "Improvement of credibility" by "Social participation /integration" factor.

\subsection{IAP analysis}

4.3.1 Analysis of community welfare centers' performance and importance in CDR According to the IPA on the performance run by community welfare centers and importance in CDR improvement, most of the sections and affiliated works were located in the "Keep up the Good Work" where both importance and performance are significant. The "self-reliance program" section was located in "Low Priority" where both importance and performance were less significant.

As to "Education/culture" and "Building network", these two sections were located in the "Possible Overkill", leading to the result of their importance being less significant despite

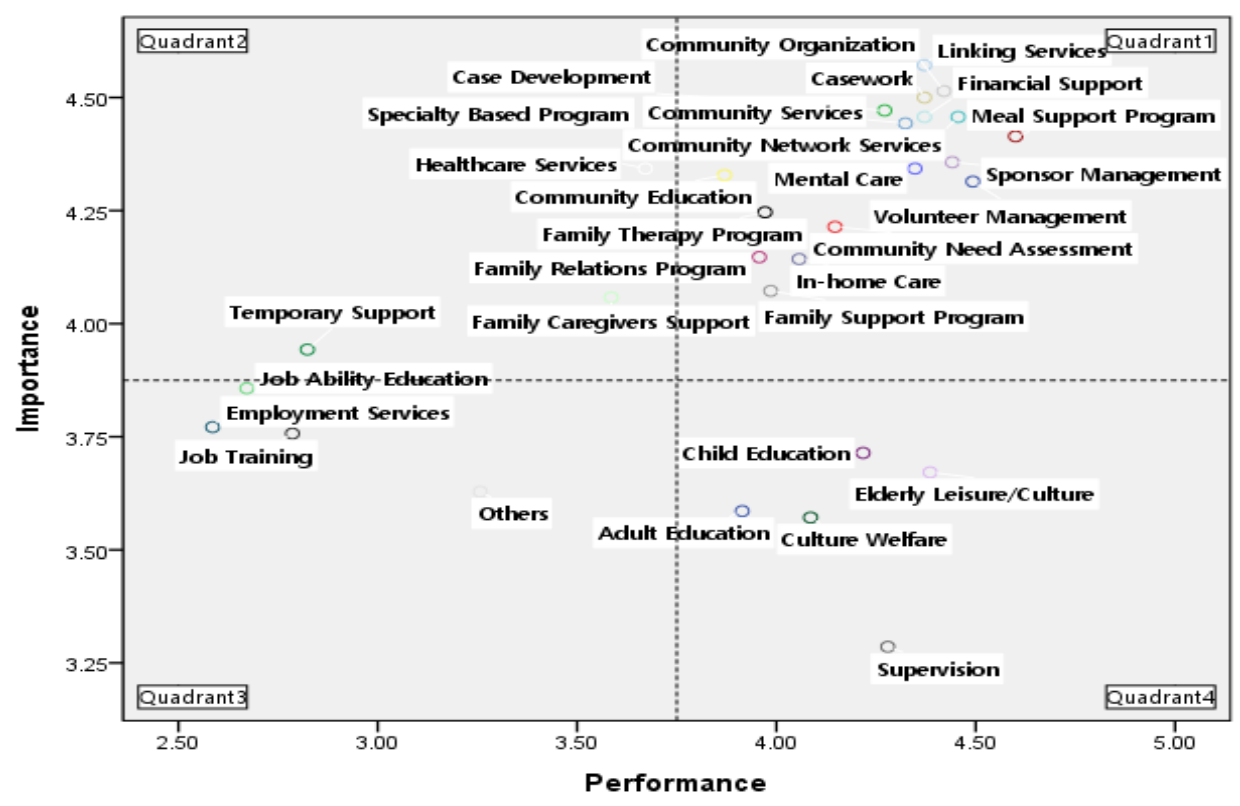

Figure 1: Analyzing performance of traditional services - importance to CDR. 
their tasks being processed in welfare centers. Examining into each service in detail, "Temporary support" had low performance even though it has importance in CDR improvement. Affiliated services of the "Self-reliance program" also were located in the "Low Priority", meaning neither its performance or importance in CDR improvement was significant. All the affiliated services of "education/culture" section were placed in the "Possible Overkill", meaning their importance in CDR improvement was less significant compared to their performance in welfare centers. Also, we can see that even for affiliated services of the same section, the workers' impression could differ, from the fact that "supervision" was placed in the "Possible Overkill" when "community network services" and "community need assessment" were placed in the "Keep up the Good Work".

\subsubsection{Importance and performance regarding CDR improvement factors}

According to the IPA on the importance and performance of the services run with respect to CDR improvement, most of the sections and affiliated services were placed in the "Keep up the Good Work" where importance and performance were both significant. The "Facilities for disaster victims" factor, "Finance" in economic elements, "Population with health insurance" factor were all placed in the "Concentrate Here" where performance was relatively low compared to importance. The "Housing" factor was placed in the "Possible Overkill", leading to its importance being low despite its performance. If we were to look at each indicator, "Disaster victim's protection services", the entire economic dimension and "housing" element affiliated indicators were located in the "Low Priority", meaning both their importance and performance were low in CDR improvement.

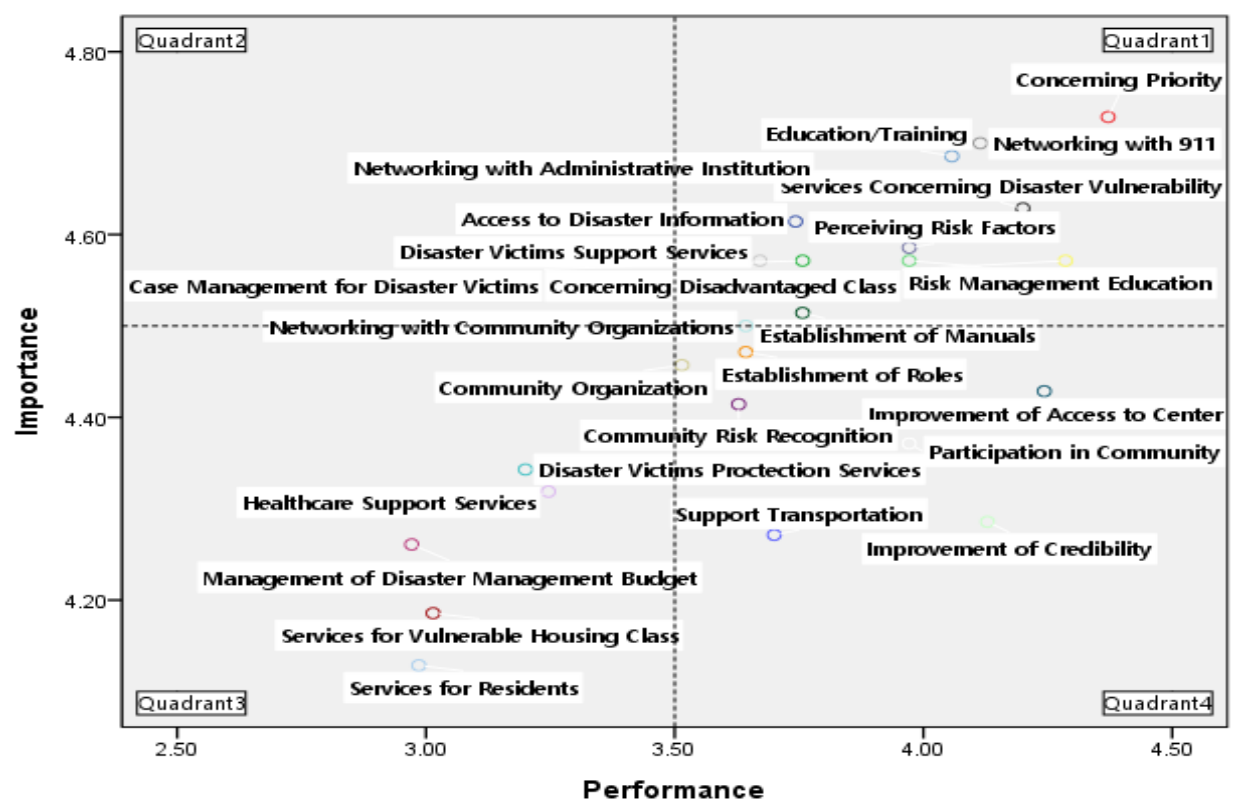

Figure 2: Analyzing performance of CDR related services - importance to CDR. 
The "Participation in community", "Community organization for response to crisis", "Improvement of credibility", "Support transportation in crisis" and all the affiliated indicators of the "Hazard occurrence" element excluding "Establishment of manuals to provide services for disaster" were placed in the "Possible Overkill", making their importance lower than their performance in terms of CDR improvement. The affiliation with "Networking with community organizations" leads to high performance but in terms of importance is placed in between the "Keep up the Good Work" and the "Possible Overkill". 12 services other than these can be found in the "Keep up the Good Work", meaning about $50 \%$ of the tasks related to CDR components possess significant importance and performance. Especially 11 services among these falls into the category of social affiliated services, indicating that community welfare centers focus on the social aspect rather than economic or physical aspects, when it comes to services related to CDR components.

\subsubsection{Summary of IPA Analysis}

The summary of the study results are organized in Table 4.

\section{DISCUSSIONS}

The summary of result and possible discussion regarding social welfare practice are following these.

First, most traditional services of community welfare centers have high importance compared to their level of performance. This means that the traditional services have a lot to do with enhancement of CDR from the viewpoint of social workers in community welfare centers.

Second, "Education/Culture sectors", "Developing/Managing Resources" are shown as low importance to CDR. It is because that those kinds of services are not directly connected to disaster management. However, CDR related services such as training program for coping with disaster risks and networking with other institutions are perceived as having high importance. Thus, it is important to develop potential disaster management programs within the range of traditional functions of community welfare centers, even though social workers express that some programs are less important to CDR.

Third, it is shown that most traditional services provided in community welfare centers need to be concerned with CDR approach as they are on the "Keep up the Good Work" area on the IPA matrix. Since the role of community welfare centers in disaster management system are ambiguous, prioritizing the services with high level of both performance and importance to CDR would help to clarify the role of community welfare centers.

Fourth, CDR improvement services have low performance in comparison with their perceived importance by social workers. Although there are no standard procedures to manage programs based on CDR improvement, social workers have the idea that improving CDR is important and it is related to their own job. Thus, training program should be provided so that the social works can take be an important participant in disaster management system.

Fifth, about half of the proposed services (12 services) linked to CDR is placed on the "Concentrate Here" area on the IPA matrix. Among those services, eleven of them belong to social dimension. It means that social workers are confident with dealing with social aspect of CDR better than other aspect (economic and physical environmental dimension). Thus, services under the social dimension can be a good example when community welfare centers provide CDR related services.

Sixth, the housing services are placed on the "Low Priority" area on the IPA matrix. This reflects that housing welfare services are not actively implementing in Korea. However, 
Table 4: Result summary.

\begin{tabular}{|c|c|c|}
\hline \multicolumn{3}{|c|}{ Quadrant 1 } \\
\hline \multirow[t]{2}{*}{ Meaning } & \multicolumn{2}{|c|}{ High Importance - High Performance/Strength } \\
\hline & CDR-CSW & CDR \\
\hline Services & $\begin{array}{l}\text { Case development, casework, } \\
\text { linking services, family } \\
\text { relations program, family } \\
\text { support program, family therapy } \\
\text { program, family caregivers } \\
\text { support, specialty based } \\
\text { program, meal support program, } \\
\text { financial support, daily life } \\
\text { support, mental care in-home } \\
\text { care, community network } \\
\text { services, community need } \\
\text { assessment, community } \\
\text { services, community } \\
\text { organization, community } \\
\text { education, volunteer } \\
\text { management, sponsor } \\
\text { management }\end{array}$ & $\begin{array}{l}\text { Services concerning disaster } \\
\text { vulnerability, concerning priority, case } \\
\text { management for disaster victims, } \\
\text { access to disaster information, risk } \\
\text { management education, perceiving risk } \\
\text { factors, networking with administrative } \\
\text { institution, networking with 911, } \\
\text { education/training, concerning } \\
\text { disadvantaged class, disaster victims } \\
\text { support services, establishment of } \\
\text { manuals, networking with community } \\
\text { organizations }\end{array}$ \\
\hline \multicolumn{3}{|c|}{ Quadrant 2} \\
\hline \multirow[t]{2}{*}{ Meaning } & \multicolumn{2}{|c|}{ High Importance - Low Performance/Weakness } \\
\hline & CDR-CSW & CDR \\
\hline Services & $\begin{array}{l}\text { Temporary support, family } \\
\text { caregivers support, healthcare } \\
\text { services }\end{array}$ & \\
\hline \multicolumn{3}{|c|}{ Quadrant 3} \\
\hline \multirow[t]{2}{*}{ Meaning } & \multicolumn{2}{|c|}{ Low Importance - Low Performance/Low priority } \\
\hline & CDR-CSW & CDR \\
\hline Services & $\begin{array}{l}\text { Job ability education, job } \\
\text { training, employment services, } \\
\text { others }\end{array}$ & $\begin{array}{l}\text { Disaster victims protection services, } \\
\text { healthcare support services, } \\
\text { management of disaster management } \\
\text { budget, services for vulnerable housing } \\
\text { class, services for residents }\end{array}$ \\
\hline \multicolumn{3}{|c|}{ Quadrant 4} \\
\hline \multicolumn{3}{|c|}{ Meaning nce - High Performance/Needless strength } \\
\hline & CDR-CSW & CDR \\
\hline Services & $\begin{array}{l}\text { Child education, adult } \\
\text { education, elderly } \\
\text { leisure/culture, culture welfare, } \\
\text { supervision }\end{array}$ & $\begin{array}{l}\text { Community organization, } \\
\text { establishment of roles, community risk } \\
\text { recognition, improvement of access to } \\
\text { center, participation in community, } \\
\text { improvement of credibility, support } \\
\text { transportation, networking with } \\
\text { community organizations }\end{array}$ \\
\hline
\end{tabular}


deteriorated buildings are totally subject to the impact of disaster. Accordingly, caring people who live in vulnerable house should not be ignored.

To sum up, the research result shows that how social workers in the community welfare centers perceive the level of performance and importance to CDR of the traditional services and proposed CDR related services that they can provide. Even though this study only covers the case of Busan, it is meaningful to suggest the role of community welfare and implication to social welfare practice.

This study was supported by BK21+.

\section{ACKNOWLEDGEMENT}

\section{REFERENCES}

[1] Holling, C.S., Resilience and stability of ecological systems. Annual Review of Ecology and Systematics, 4, pp. 1-23, 1973.

[2] Rutter, M., Resilience in face of adversity: Protective factors and resilience to psychiatric disorder. British Journal of Psychiatry, 147(6), pp. 598-611, 1985.

[3] Olsson, C.A., Bond, L., Burns, J.M., Vella-Brodrick, D.A. \& Sawyer, S.M., Adolescent resilience: A conceptual analysis. Journal of Adolescence, 26(1), pp. 1-11, 2003.

[4] Hong, E., Conceptual understanding of resilience and instructional suggestion. Korean Journal of Special Education, 41(2), pp. 45-67, 2006.

[5] Shin, W., Kim, M. \& Kim, J., Developing Measures of Resilience for Korean Adolescents and Testing Cross, Convergent, and Discriminant Validity, Studies on Korean youth, 20(4), pp. 105-131, 2009.

[6] Timmerman, P., Vulnerability Resilience and Collapse of Society: A Review of Models and Possible Climatic Applications, University of Toronto, 1981.

[7] Kim, H., Kim, T. \& Lee, G., Classifying the urban elements and setting up the directions for developing urban disaster prevention standard, National Disaster Management Institute: Seoul, 2010.

[8] Mayunga, J.S., Measuring the Measure: A Multi-Dimensional Scale Model to Measure Community Disaster Resilience in the U.S, Gulf Coast Region, Texas A\&M University, 2009.

[9] Kang, S., A Study on the Concept and Future of Community Disaster Resilience for Natural Disasters, Planning and Policy, pp. 21-29, 2014.

[10] Kwon, T., Yang, G., Oh, K. \& Lee, E., Sustainable Disaster Management: Activity Programs for the Community-based Disaster Prevention Organizations. The Korean Journal of Local Government Studies, 12(1), pp. 107-131, 2008.

[11] Centre for International Studies and Cooperation(CECI), Framework on community based disaster risk management in Vietnam, Canada: Joint Advocacy Networking Initiative in Vietnam, 2011.

[12] Ha, H., Kim, C., Cho, K., Lee, S., Choi, J. \& Jeon, D., Critical Investigation on Community Disaster Resilience and Public Administrative Suggestion. Regional development research, 23, pp. 409-464, 2014.

[13] Lee, J. \& Kim, H., A Study of Governance Conducting in National Disaster Response Process: comparison between South Korea and China. Modern Chinese research, 16(2), pp. 43-80, 2015.

[14] Yang, G., Strategies of Building Disaster Resistant Communities. The Korea Contents Society, 9(5), pp. 249-256, 2009. 
[15] Ministry of Health \& Welfare, Business handling Guidelines for Operation Related to Social Welfare Center, Seoul, 2016.

[16] Mi, J.C., The role of regional social welfare centers in a special disaster area, the Graduate School of Public Administration Chung-Ang University, 2015.

[17] Yoon, D.K., Kang, J.E. \& Brody, S.D., A measurement of community disaster resilience in Korea. Journal of Environmental Planning and Management, 59(3), pp. 436-460, 2016.

[18] Mayunga, J.S., Measuring the Measure: A Multi-Dimensional Scale Model to Measure Community Disaster Resilience in the U.S. Gulf Coast Region, Texas A\&M University, 2009.

[19] Cutter, S.L., Burton, C.G. \& Emrich, C.T., Disaster Resilience Indicator for Benchmarking Baseline Conditions. Journal of Homeland Security and Emergency Management, 7(1), pp. 1-22, 2010.

[20] Burton, J.S., The Development of Metrics for Community Resilience to Natural Disaster, University of South Carolina, 2012.

[21] Kim, H., Shim, S., Oh, K., Kim, M. \& Choe, D., Development of Community Resilience Framework, Seoul: National Disaster Management Institute, 2012.

[22] Kang, S., Cho, S. \& Hong, S., A Policy Implication for Community Resilience from Natural Disasters. Gyeonggi Research Institute basic research, pp. 1-102, 2013.

[23] Mun, S., A Study on IPA of Community Welfare Center Programs. Journal of community welfare, 53, pp. 51-83, 2015. 